«Системні технології» 4 (129) 2020 «System technologies»

DOI 10.34185/1562-9945-4-129-2020-13

УДК 681.3.068

В.М. Безуб

\title{
ВИКОРИСТАННЯ НЕЧІТКОГО РЕГУЛЯТОРА ДЛЯ УПРАВЛІННЯ ПРОЦЕСОМ ГРАНУЛЯЦІЇ ОБКОТИШІВ
}

Анотація. Показано недоліки існуючих моделей процесу грануляції обкотишів при використанні моделей для побудови систем управління грануляторами. Запропоновано для побудови регулятора використовувати нечіткі моделі процесу гранулящії обкотишів. Ключові слова: грануляція обкотишів, управління гранулятором, нечіткі моделі.

Постановка проблеми. Поширеним способом отримання сирих окотишів є використання чашових грануляторів [2, 4]. У склад такого гранулятора входить чаша, що обертається з певною швидкістю. Спеціально підготовлена шихта скочується по похилій поверхні чаші, формуючи грудочки, гранули.

Шихта для виробництва окотишів складається 3 магнетитового концентрату і сполучної добавки бентоніту (для флюсованих обкотишів в шихту додається вапняк). Регулюючи швидкість обертання чаші, кут іiі нахилу, інтенсивність потоку шихти, інтенсивність ї̈ зволоження можна впливати на процес отримання сирих окотишів.

На процес формування сирих окотишів впливає ступінь подрібнення концентрату, хімічний склад шихти і бентоніту. Також функціонування чашового гранулятора залежить від того, як використовується площа чаші. Оптимальним вважається режим, коли відрив дрібних фракцій відбувається в верхній точці діаметра [3]. Такий режим забезпечує використання для процесу формування окотишів максимальної площі чаші. Збільшення швидкості обертання чаші викликає зростання відцентрових сил, що перешкоджають скочуванню окотишів вниз. Тому із збільшенням швидкості обертання чаші збільшують кут іiі нахилу до горизонту. Граничне значення кута нахилу чаші визначається

(C) Безуб B.М., 2020

138

ISSN 1562-9945 (Print)

ISSN 2707-7977 (Online) 
«Системні технології» 4 (129) 2020 «System technologies»

властивостями матеріалу, що гранулюється i потрібним розміром окотишів.

При правильному веденні технології процесу необхідно збереження розміру придатних до подальшої обробки окотишів на постійному рівні, що вимагає регулювання процесу отримання сирих окотишів. Зменшення розміру гранул при постійному потоці шихти вимагає збільшення швидкості обертання чаші гранулятора або зменшення кута нахилу чаші і зволоження шихти. Зазвичай для збільшення розміру окотишів достатнім є збільшення швидкості обертання чаші гранулятора, що забезпечує підняття окотишів на більшу висоту. Але при цьому потрібно попереджувати попадання окотишів в зону завантаження шихти.

Мета роботи. Метою роботи є побудова нечіткої моделі процесу грануляції обкотишів для використання моделі при створенні регулятора, що виконує управління гранулятором.

Результати досліджень. Вивчення технологічної документації показує, що основні залежності процесу грануляції описані в основному в якісних термінах. Відомі моделі процесу грануляції виконано методами ймовірно-статичного аналізу $[1,5]$, що не сприяє побудові стійкої детермінованої моделі процесу для потреб створення системи управління гранулятором.

Таким чином доцільним є описання процесу грануляції методами нечіткої логіки. Вирішення задач фазифікації і дефазифікації було здійснено по [6].

Після вивчення теорії грануляції сипких матеріалів, технологічних карт процесу та опитування персоналу було визначено описуючі процес грануляції обкотишів лінгвістичні змінні: 
«Системні технології» 4 (129) 2020 «System technologies»

Таблиця 1

Перелік нечітких змінних

\begin{tabular}{|c|c|c|c|c|c|}
\hline $\begin{array}{l}\text { Вхідні } \\
\text { змінні }\end{array}$ & № & Назва & \multicolumn{3}{|c|}{ Значення } \\
\hline & 1 & Вологість шихти & В (висока) & С (середня) & Н (низька) \\
\hline & 2 & Вихід придатного & В (високий) & $\begin{array}{l}\text { C } \\
\text { (середній) }\end{array}$ & Н (низький) \\
\hline & 3 & $\begin{array}{l}\text { Продуктивність } \\
\text { гранулятора }\end{array}$ & В (висока) & С (середня) & Н (низька) \\
\hline & 4 & Кут нахилу чаші & В (високий) & $\begin{array}{l}\text { C } \\
\text { (середній) }\end{array}$ & Н (низький) \\
\hline & 5 & $\begin{array}{l}\text { Швидкість обер- } \\
\text { тання чаші }\end{array}$ & В (висока) & С (середня) & Н (низька) \\
\hline & 6 & $\begin{array}{l}\text { Інтенсивність } \\
\text { зволоження }\end{array}$ & В (висока) & С (середня) & Н (низька) \\
\hline \multirow[t]{4}{*}{$\begin{array}{l}\text { Вихідні } \\
\text { змінні }\end{array}$} & № & Назва & \multicolumn{3}{|c|}{ Значення } \\
\hline & 1 & $\begin{array}{l}\text { Регулювання кута } \\
\text { нахилу чаші }\end{array}$ & $\begin{array}{l}\text { С (зменши- } \\
\text { ти) }\end{array}$ & $\begin{array}{l}\text { H } \\
\text { змінювати) }\end{array}$ & $\begin{array}{l}\text { У } \\
\text { (збільшити) }\end{array}$ \\
\hline & 2 & $\begin{array}{l}\text { Регулювання } \\
\text { швидкості обер- } \\
\text { тання чаші }\end{array}$ & $\begin{array}{l}\text { СС (сильно } \\
\text { знизити) } \\
\text { С (знизити) }\end{array}$ & $\begin{array}{l}\text { H } \quad \text { (не } \\
\text { змінювати) }\end{array}$ & $\begin{array}{l}\text { У } \\
\text { (збільшити) } \\
\text { СУ (сильно } \\
\text { збільшити) }\end{array}$ \\
\hline & 3 & $\begin{array}{l}\text { Регулювання } \text { ін- } \\
\text { тенсивності } \\
\text { лово- } \\
\text { ложення }\end{array}$ & С (знизити) & $\begin{array}{l}\text { H } \quad \text { (не } \\
\text { змінювати) }\end{array}$ & $\begin{array}{l}\text { У } \\
\text { (збільшити) }\end{array}$ \\
\hline
\end{tabular}

Функції належності будуються для переходу від якісного нечіткого описання змінних до формалізованого. Будемо використовувати:

- трапеційні функції належності, що мають область толерантності, корелюючи (по змінній) з зоною оптимальності процесу;

- трикутні функції належності, що мають виражений екстремум. 
«Системні технології» 4 (129) 2020 «System technologies»

На рис. 1 представлені функції належності для вхідних змінних.

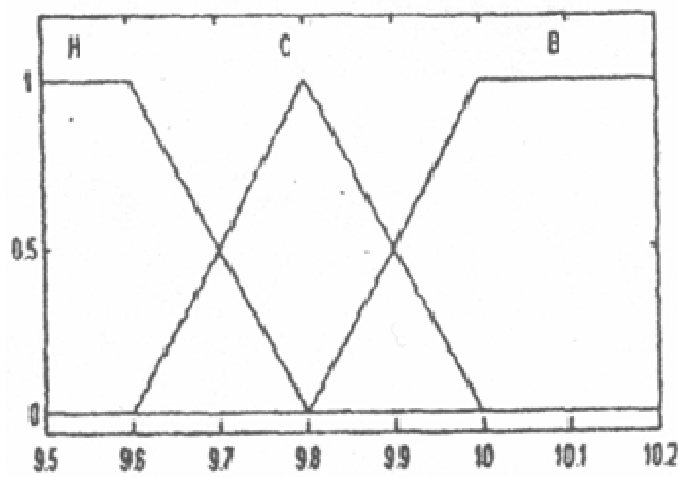

а) змінна “Вологість шихти”

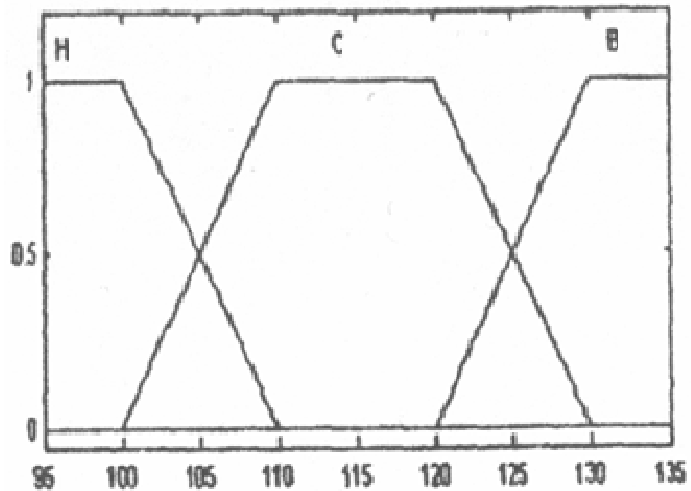

в) змінна “Продуктивність гранулятора”

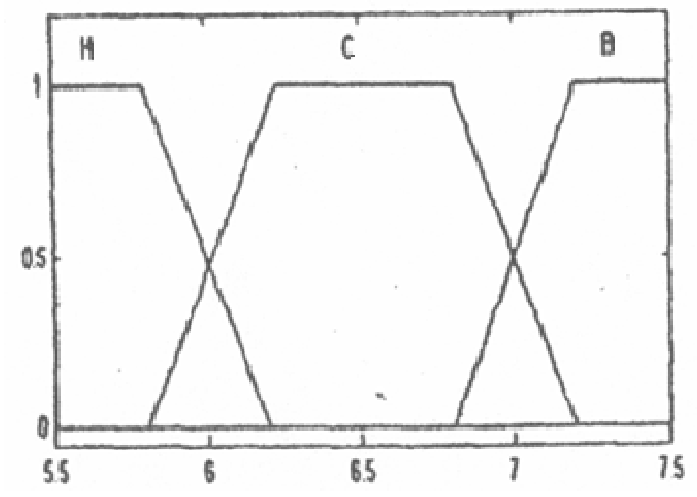

д) змінна “Швидкість обертання чаші”

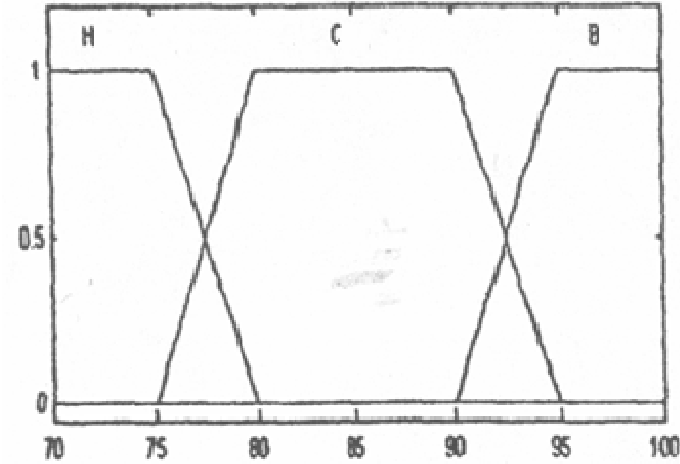

б) змінна “Вихід придатного”

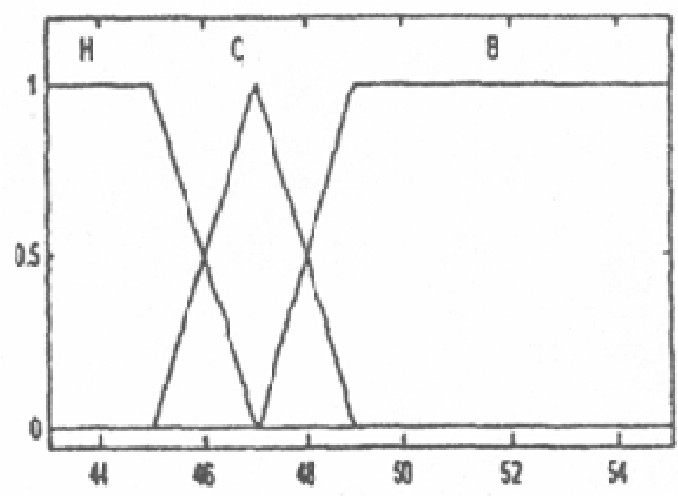

г) змінна “Кут нахилу чаші”

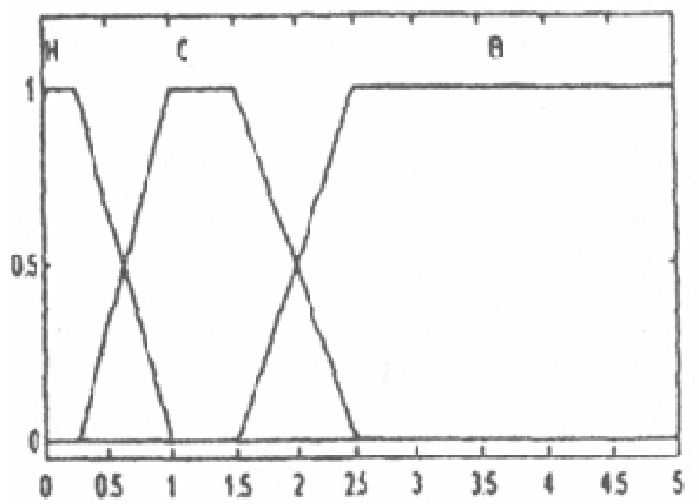

є) змінна “Інтенсивність зволоження"

Рисунок 1 - Функції належності для вхідних змінних

На рис. 2 представлені функції належності для вихідних змінних. 
«Системні технології» 4 (129) 2020 «System technologies»

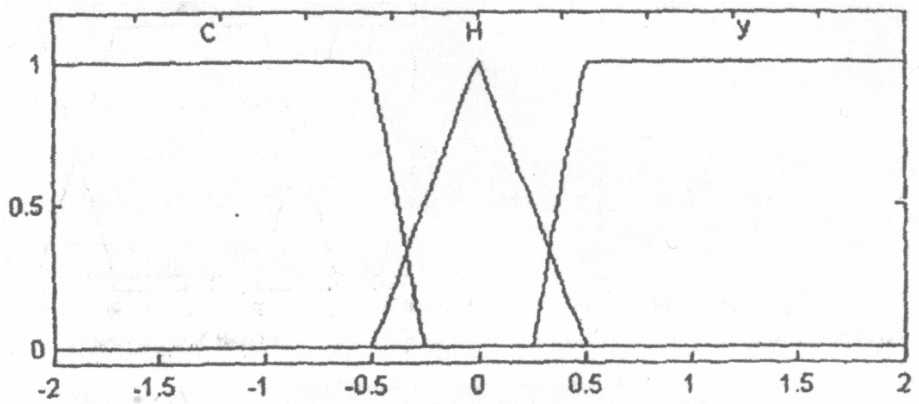

а) змінна “Регулювання кута нахилу чаші”

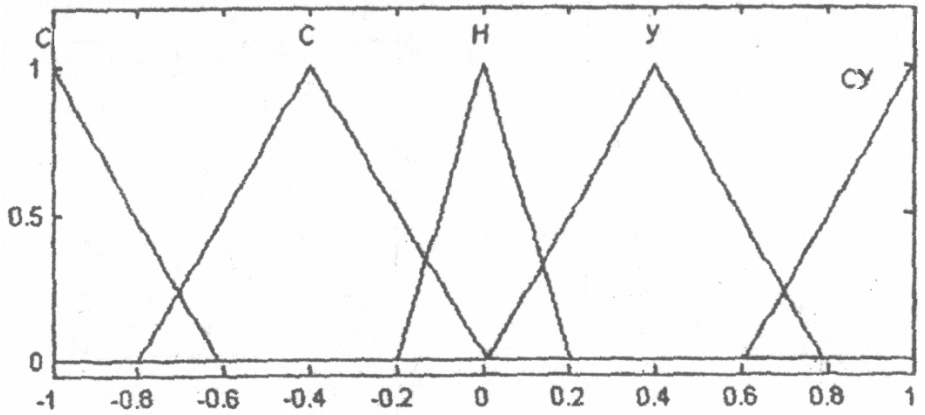

б) змінна “Регулювання швидкості обертання чаші”

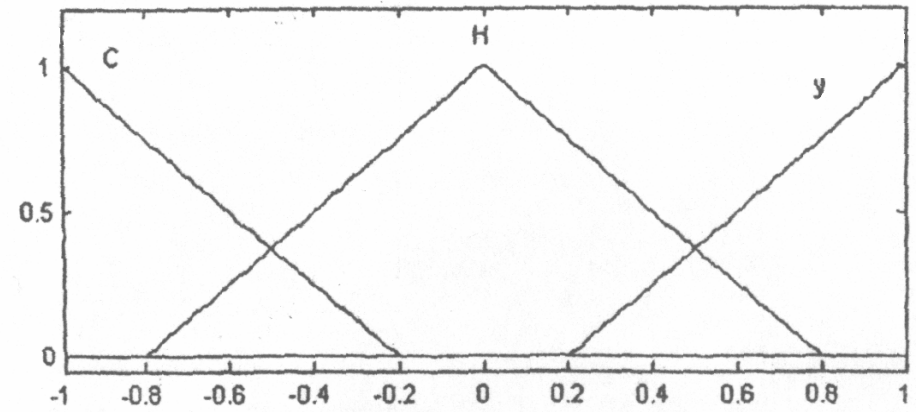

в) змінна “Регулювання інтенсивності зволоження”

Рисунок 2 - Функції належності для вихідних змінних

Використовуючи результати опитування технологів та експертів була побудована (табл. 2) база правил щодо типових виробничих ситуацій в процесі грануляції. Тут використовуються наступні позначення:

Н значення “низьке” вхідної змінної

C значення “середнє” вхідної змінної

В значення “високе” вхідної змінної

CC значення “сильно знизити” вихідної змінної

C значення “знизити” вихідної змінної 
«Системні технології» 4 (129) 2020 «System technologies»

H значення “не змінювати” вихідної змінної

у значення “підвищити” вихідної змінної

СУ значення “сильно підвищити” вихідної змінної

Таблиця 2

Таблиця правил

\begin{tabular}{|c|c|c|c|c|c|c|c|c|c|c|c|c|c|}
\hline \multirow{3}{*}{$\begin{array}{c}\text { Входи } \\
\text { та ви- } \\
\text { ходи }\end{array}$} & \multicolumn{13}{|c|}{ Типові ситуації } \\
\hline & № & 1 & 2 & 3 & 4 & 5 & 6 & 7 & 8 & 9 & 10 & 11 & 12 \\
\hline & & & & & & & & & & & & & \\
\hline \multirow{6}{*}{$\begin{array}{c}\text { Входи } \\
\text { (вхідні } \\
\text { змінні) }\end{array}$} & 1 & $\mathrm{H}$ & $\mathrm{H}$ & $\mathrm{H}$ & $\mathrm{H}$ & $\mathrm{C}$ & $\mathrm{C}$ & $\mathrm{C}$ & $\mathrm{C}$ & B & B & B & B \\
\hline & 2 & $\mathrm{H}$ & $\mathrm{H}$ & $\mathrm{C}$ & $\mathrm{C}$ & B & B & $\mathrm{H}$ & $\mathrm{H}$ & $\mathrm{C}$ & $\mathrm{C}$ & B & $\mathrm{H}$ \\
\hline & 3 & $\mathrm{H}$ & B & $\mathrm{H}$ & $\mathrm{C}$ & $\mathrm{H}$ & B & $\mathrm{H}$ & $\mathrm{C}$ & $\mathrm{H}$ & B & $\mathrm{H}$ & B \\
\hline & 4 & $\mathrm{C}$ & $\mathrm{H}$ & $\mathrm{H}$ & B & $\mathrm{C}$ & $\mathrm{H}$ & B & $\mathrm{H}$ & $\mathrm{C}$ & $\mathrm{H}$ & $\mathrm{C}$ & $\mathrm{H}$ \\
\hline & 5 & $\mathrm{H}$ & $\mathrm{H}$ & B & $\mathrm{C}$ & B & B & $\mathrm{C}$ & $\mathrm{C}$ & B & $\mathrm{H}$ & $\mathrm{C}$ & B \\
\hline & 6 & $\mathrm{H}$ & $\mathrm{H}$ & $\mathrm{C}$ & B & $\mathrm{H}$ & B & $\mathrm{H}$ & $\mathrm{C}$ & $\mathrm{H}$ & $\mathrm{C}$ & $\mathrm{H}$ & $\mathrm{H}$ \\
\hline \multirow{3}{*}{$\begin{array}{c}\text { Виходи } \\
\text { (вихідні } \\
\text { змінні) }\end{array}$} & 1 & $\mathrm{y}$ & $\mathrm{H}$ & $\mathrm{y}$ & $\mathrm{C}$ & $\mathrm{H}$ & $\mathrm{H}$ & $\mathrm{C}$ & $\mathrm{y}$ & $\mathrm{y}$ & $\mathrm{H}$ & $\mathrm{H}$ & $\mathrm{y}$ \\
\hline & 2 & СУ & $\mathrm{y}$ & $\mathrm{C}$ & $\mathrm{y}$ & $\mathrm{H}$ & $\mathrm{H}$ & $\mathrm{H}$ & $\mathrm{C}$ & CC & $\mathrm{H}$ & $\mathrm{C}$ & CC \\
\hline & 3 & $\mathrm{y}$ & $\mathrm{y}$ & $\mathrm{H}$ & $\mathrm{H}$ & $\mathrm{H}$ & $\mathrm{C}$ & $\mathrm{y}$ & $\mathrm{H}$ & $\mathrm{C}$ & $\mathrm{C}$ & $\mathrm{C}$ & $\mathrm{C}$ \\
\hline
\end{tabular}

Існуючі на грануляторі:

- система стабілізації кута нахилу чаші;

- система стабілізації швидкості обертання чаші;

- система управління зволоженням шихти;

отримують завдання від дефазифікованих вихідних змінних нечіткої системи управління у відповідності з табл.2, а існуючі на грануляторі:

- вимірювач числа обертів чаші;

- вимірювач кута нахилу чаші;

- вологості шихти;

- витратомір води

фазифікуються та використовуються у якості вхідних змінних.

Висновки. В результаті досліджень встановлено можливість і потенційна ефективність (особливо в частині застосування слабко 
«Системні технології» 4 (129) 2020 «System technologies»

формалізованих знань досвідчених експертів) нечітких алгоритмів при управлінні гранулятором обкотишів.

Їх використання забезпечує подальше підвищення стабільності роботи гранулятора і якості обкотишів.

\section{ЛITEРАТУРА / ЛИТЕРАТУРА}

1. Берман Ю.А. Основные закономерности производства окатышей. - Челябинск: Металлургия, 1991.

2. Вегман Е.Ф. Окомкование руд и концентратов; учебник для техникумов. - 3-е изд. - М.: Металлургия, 1984.

3. Информационные системы в экономике / Под ред. В.В.Дика. - М.: Финансы и статистика, 1996.

4. Ларичев О.И., Поляков О.А. Человеко-машинные процедуры решения многокритериальных задач математического программирования (об3ор)// Экономика и математические методы, 1980. - T.XVI. - Вып. 1. C. $129-145$.

5. Черняк К.И. Системный анализ в управлении экономикой. М.: Экономика, 1975.

6. Еременко Ю.И., Боева Л.М., Кузнецов Л.А., Крахт В.Б. Повышение АСУ горно-металлургического производства на основе интеллектуализации управления: Монография. - Старый Оскол: ООО “ТНТ”, 2005.

\section{REFERENCES}

1. Berman Yu.A. Osnovnyie zakonomernosti proizvodstva okatyishey. Chelyabinsk: Metallurgiya, 1991.

2. Vegman E.F. Okomkovanie rud i kontsentratov; ucheb $\neg$ nik dlya tehnikumov. - 3-e izd. - M.: Metallurgiya, 1984.

3. Informatsionnyie sistemyi v ekonomike / Pod red. V.V.Dika. - M.: Finansyi i statistika, 1996.

4. Larichev O.I., Polyakov O.A. Cheloveko-mashinnyie pro $\neg$ tseduryi resheniya mnogokriterialnyih zadach matematicheskogo programmirovaniya (ob-zor) // Ekonomika i matematicheskie metodyi, 1980. - T.XVI. - Vyip. 1. - S. 129-145.

5. Chernyak K.I. Sistemnyiy analiz v upravlenii ekonomikoy. M.: Ekonomika, 1975.

6. Eremenko Yu.I., Boeva L.M., Kuznetsov L.A., Kraht V.B. Povyishenie ASU gorno-metallurgicheskogo proizvodstva na osnove intellektuali-zatsii upravleniya: Monografiya. - Staryiy Oskol: OOO “TNT”, 2005. 


\section{«Системні технології» 4 (129) 2020 «System technologies»}

Использование нечеткого регулятора

для управления процессом окомкования окатышей

Показаны недостатки существующих моделей процесса окомкования окатышей при использавании моделей для построения систем управления окомкователями. Предложено для построения регулятора использовать нечеткие модели процесса окомкования окатышей.

\section{Using of fuzzy regulator to control the process of granulating of pellets}

Widespread way of producting crude granuls is use bowl granulators. The bowl is a part of such granulator that rotates with a certain speed. Specially prepared furnace charge rolls down an inclined surface of a bowl, forming lumps, granules. Furnace charge for production granuls consists of magnetite of a concentrate and bentonite binding additive (for gumboil granuls in furnace charge limestone is applied). Regulating the speed of rotation of a bowl, a corner of its inclination, intensity of a stream of furnace charge, intensity of its moistening it is possible to influence process of receiving crude granuls.

Process of formation crude granules is influenced by extent of concentrate crushing, the chemical composition of furnace charge and bentonite. Also functioning of the bowl granulator depends on how the area of a bowl is used. The mode when the lead of small fractions occurs in the top point of diameter is considered optimum. Such mode provides uses for granules formation process to the maximum area of a bowl. Increase in speed of rotation of a bowl causes growth of the centrifugal forces interfering rolling granules down. Therefore with increase in speed of rotation of a bowl increase a corner of its inclination to the horizon. The extreme value of a tilt angle of a bowl is defined by properties of material that shredded and the necessary granules size.

At the correct maintaining technology of process preservation of the size suitable to further granules processings at the constant level is necessary that demands regulation of process of receiving crude granules. The known models of process of granulation it is executed by methods of possibly static analysis that does not promote creation of the steady determined process model for needs to creation of a control system of the granulator.

The purpose of work is creation of indistinct model of process of granulation for use of model during creation of the regulator that carries out controls of the granulator.

As a result of researches it is established an opportunity and potential efficiency (especially regarding use of poorly formalized knowledge of skilled experts) indistinct algorithms at control of the granulator. Their use provides further increase in stability of granulator operation and quality of granules.

Безуб Владимир Николаевич - Национальная металлургическая академия Украины.

Безуб Володимир Миколайович - Національна металургійна академія України.

Bezub Vladymir - The National Metallurgical Academy of Ukraine. 